\section{Traducción, intraductibilidad y simulacro en la política mapuche*}

\section{Translation, untranslatable and simulacrum in Mapuche politics}

\author{
André MenARD*
}

\section{Resumen}

Se propone una entrada a esta cuestión de la intraductibilidad, pero desde un abordaje más bien oblicuo respecto de su desarrollo propiamente lingüístico o filológico, es decir deteniéndome en el análisis de los distintos tratamientos, conceptualizaciones o formulaciones de algo como la intraducibilidad en tanto dispositivo de argumentación política en torno a lo mapuche a lo largo del siglo XX. En este marco deberemos recurrir a una noción amplia de la traducción, Ilevándola fuera de su acepción estrictamente lingüística, hacia el problema más general que implican las diferentes figuras de la mediación, no sólo entre etnias o naciones, sino que también entre instituciones y demandas políticas. Se concluye con una reflexión en torno a la relación entre traducción y simulacro, explorando las potencias políticas de este último a la hora de politizar, mediante su desnaturalización, los ordenamientos coloniales o más recientemente multiculturales, y sus políticas de la identidad.

Palabras claves: traducción, intraducible, política mapuche, mimesis, simulacro.

\begin{abstract}
An entry to the question of untranslatability is proposed from a rather oblique approach to its linguistic or philological development, that is to say, focusing in the analysis of the different treatments, conceptualizations or formulations of the untranslatability as a device of political argumentation by and on the Mapuche people throughout the twentieth century. In this framework we will have to resort to a broad
\end{abstract}


notion of translation, trying to go beyond its strictly linguistic meaning, to reach the more general problem implied by the different figures of mediation, not only between ethnic groups or nations, but also between institutions and political demands. It concludes with a reflection on the relationship between translation and simulacrum, exploring the political powers of the latter in order to politicize, through its denaturalization, the colonial or more recently multicultural orderings, and their identity policies.

Key words: translation, untranslatable, Mapuche politics, mimesis, simulacrum.

\section{Traducción e intraducible}

Entre la traducción al mapudungun de "Dios" por "Dios" en el diccionario del jesuita Luis de Valdivia a principios del sigloXVII y los más recientes textos de intelectuales mapuche, escritos en castellano, pero trufados de términos en mapudungun, se intuye la posibilidad de elaborar algo como un diccionario de intraducibles mapuche-castellano ${ }^{1}$ (un poco a la manera de ese Vocabulario filosófico europeo dirigido por Barbara Cassin (2004), y cuyo subtítulo era "diccionario de intraducibles"). Sin embargo, y pese a lo necesario de un proyecto de este tipo, en esta ocasión propondré una entrada a la cuestión de la intraductibilidad, pero desde un abordaje más oblicuo respecto de su desarrollo propiamente lingüístico o filológico, es decir deteniéndome menos (o nada) en el trabajo de identificación y estudio de esos términos o conceptos intraducibles o intraducidos, y más en el análisis de los distintos tratamientos, conceptualizaciones o formulaciones de algo como la intraducibilidad en tanto dispositivo de

Intuición que le debo a Esteban Radiszcz. argumentación política en torno a lo mapuche a lo largo del siglo XX. En este marco deberemos recurrir a una noción amplia de la traducción, llevándola fuera de su acepción estrictamente lingüística, hacia el problema más general que implican las diferentes figuras de la mediación, no sólo entre etnias o naciones, sino que incluso entre conceptos y experiencias o entre instituciones y demandas políticas, por nombrar solo algunas de ellas.

En el caso de la historia mapuche post-reduccional, este abordaje de la traducción en un sentido amplio, se puede formular a partir del juego o de la tensión que cruza la articulación entre, por un lado la necesidad de traducir ciertas demandas en un formato institucional -pero también simbólico o estético- que sea legible según los marcos o códigos jurídico-políticos dominantes (tanto nacional como internacionalmente), y por otro lado, la necesidad simultánea de afirmar la existencia de una diferencia -lo mapucheirreductible a esos mismos marcos y códigos. Es así que lo mapuche, como en otro momento lo araucano, han marcado el lugar de este juego entre traducible e intraducible, juego doble pues, por una parte, implica el intento de traducción, por parte del Estado, de la especificidad de una demanda irreductiblemente étnica, nacional o cultural, a cierto lenguaje general de las demandas que gestiona, es decir segmentándola en demandas por tierra, por educación, por conservación de tradiciones, por autonomía territorial, por protección del medioambiente, por acceso al crédito, etc. $Y$ por otra parte implica el gesto paralelo de una traducción de lo mapuche, y desde lo mapuche, como significante de una demanda integral y por lo tanto no codificable, es decir no traducible (al menos no plenamente) según los criterios del Estado, a ciertas estrategias de movilización y de organización 
legibles y eficaces según el contexto históricopolítico.

Estoy pensando aquí, por ejemplo, en la evolución a lo largo del siglo XX de las formas y los nombres de las organizaciones mapuche: a principios del siglo, en medio de la ola asociativa del mutualismo que reunía a artesanos, obreros y otros actores de la sociedad chilena, es cuando aparece la Sociedad Caupolicán Defensora de la Araucanía (1910) o la Sociedad Mapuche de Protección Mutua (1916). En los tiempos de la Federación Obrera de Chile (1919) surgirá la Federación Araucana (1921). Más tarde, sectores cercanos al Frente Popular de Aguirre Cerda fundarán el Frente Único Araucano (1937). En torno al corporativismo de Ibáñez del Campo se constituirá la Corporación Araucana (1938), que con Venancio Coñuepan a la cabeza y de ministro de tierras y colonización dará lugar a la Dirección de Asuntos Indígenas (1952). Más tarde y en el contexto de la reforma agraria y la articulación del movimiento mapuche con partidos chilenos de izquierda aparecerán en los años sesenta movimientos como la Cooperativa Lautaro de Lumaco, la Confederación Campesina e Indígena Ranquil o la Unión Campesina Revolucionaria. ${ }^{2}$ Luego, durante la dictadura, el movimiento mapuche volverá a recodificar estratégicamente su nombre bajo la forma de una asociación gremial, la Asociación Gremial de Pequeños Campesinos y Artesanos Mapuche Ad Mapu (1981).

Ahora bien, lo interesante es que este movimiento de traducción de la demanda mapuche a códigos jurídica y políticamente legibles variará con el fin de la dictadura, y el desplazamiento

Una excepción a esta lógica de nominación de los movimientos es el caso del Movimiento Netuaiñ Mapu, pero que pese a su nombre en mapudungun seguía la misma forma de traducción política mapuche a los códigos de clase y campesinistas de los movimientos contemporáneos. correlativo de las ideologías desarrollistas e indigenistas, hacia un modelo multicultural de gestión de las diferencias étnicas (así como por sus lecturas más críticas de corte intercultural o indianista), dando lugar a organizaciones y actores mapuche que, en cierta forma, se proponen eludir ese trabajo de traducción directa de sus demandas al vocabulario organizacional chileno, reivindicando ciertas figuras "originarias" y por lo tanto intraducibles de la política y de la representación mapuche. Pienso específicamente en el surgimiento de la figura del werken (mensajero o portavoz) levantada por el Consejo de Todas las Tierras (1991) en su rechazo explícito a las formas partidistas y organizacionales chilenas, o más tarde en la Coordinadora Arauco Malleco y su reivindicación de la figura del weichafe (guerrero) como forma privilegiada del actor político mapuche. Lo interesante de este proceso político es que se desarrolla en paralelo al ya señalado surgimiento dentro de los discursos políticos y académicos mapuche escritos en castellano, del uso cada vez más sistemático de términos intraducidos o intraducibles como el tuwün (territorio de origen) y el küpalme (linaje), o el kimün (saber, conocimiento) y el rakiduam (pensamiento), por nombrar sólo algunos.

En cuanto gesto lingüístico-político, esta -aparente- ${ }^{3}$ interrupción de la traducción podría leerse como la afirmación, a través del uso de

\footnotetext{
Y digo aparente al tomar en cuenta las más actuales teorías de la traducción y su superación de la figura del traductor como traidor de un sentido original, y que la consideran más bien como un trabajo de producción de sentidos no falsos, sino que complementarios al del texto original, en línea por ejemplo con la conceptualización que hace Walter Benjamín de la "tarea del traductor" (Benjamin 2010). La asociación que aquí se propone entre esta noción de traducción y la de un simulacro afirmativo busca justamente relevar esta comprensión de la traducción como producción de nuevos sentidos más que como ocultamiento, traición o simulacro (entendido negativamente) de ese supuesto sentido original.
} 
esos términos en mapudungun, de un sentido culturalmente inmediato, un sentido aun no desvirtuado por la traducción, un sentido auténtico, original y originario, aun no caído en los simulacros de sentido con que lo disfrazan los términos wingka. Ahora bien, el que términos como kimün o rakiduam aparezcan como islas de autenticidad en textos producidos en el ámbito académico y escritos en castellano, o que el cargo de werken designe por ejemplo en el caso de Aucan Huilcaman a un portavoz de demandas de un sujeto mapuche a nivel nacional (no sólo comunitario) e incluso internacional, ya podría leerse como una forma de traducción (por no decir una traición) respecto de su uso en contextos sociales y lingüísticos "originales". El problema es que esta posible objeción se puede recusar argumentando que el sentido de los términos no es anterior a los destinos pragmáticos de su uso, o dicho en otras palabras, que la distinción entre su denotación original y sus connotaciones históricas contingentes no se puede zanjar tan automáticamente, es decir que la historia de los usos de una palabra como werken, asociada por ejemplo al surgimiento de una organización como el Consejo de Todas las Tierras o al recurso por parte del movimiento mapuche a instrumentos jurídicos internacionales como el Convenio 169 de la OIT, no es disociable de aquello que constituye su sentido.

Esta comprensión histórica y pragmática del sentido de los términos suspende, por lo tanto, la jerarquización entre un uso original y uno desvirtuado de las palabras. $Y$ esto tanto a uno como al otro lado de la traducción, pues lo mismo podría decirse del recurso por parte del movimiento mapuche a términos como "federación", "corporación" o "presidente", términos que, en su reemplazo noventero por palabras en mapudungun, aparecían también como formas traicioneras, es decir como simulacros (colonizados) de expresión de ciertos sentidos propiamente mapuche de la organización o de la autoridad. Pero siguiendo el mismo razonamiento histórico y pragmático, podríamos decir que, al ser usados al servicio de una causa mapuche, el uso de estos términos los llevaba más allá de sus contextos sociales y lingüísticos occidentalmente o chilenamente "originales". Y por causa mapuche me refiero a una causa basada en la afirmación de una distinción étnica, nacional o cultural -o, en otras palabras, a la afirmación de una intraductibilidad política de fondo- así como a una resistencia frente los intentos estatales por anular dicha diferencia. Se dibuja así una política de la lengua basada justamente en la crítica de estos supuestos de originalidad, en una suerte de profanación del límite que marcaría un sentido propio de uno figurado. Al final de este texto retomaremos esta cuestión bajo la forma de la relación entre traducción y simulacro, entendiendo a este último como una interrupción de los ordenamientos políticos basados en el postulado de un sentido original y originario.

Esto nos llevará a preguntarnos por lo que significa descolonizar, en la medida en que este uso reciente de los términos en mapudungun en contextos políticos y académicos se suele entender en los términos de un proyecto de descolonización, pero que muchas veces sigue perpetuando lo que podemos entender como una forma colonial de ordenar la lengua, es decir como un orden que jerarquiza entre un sentido original y los simulacros -las traduccionesde este sentido. Pero antes de abordar esta pregunta es necesario volver al problema de lo intraducible como un dispositivo en torno al 
cual se ha desarrollado esa relación colonial. De hecho, parte de los nuevos sentidos que han adquirido palabras como werken o weichafe en sus usos recientes, tienen que ver con el hecho de estar significando ese lugar de lo intraducible que, como veremos, otros términos han significado a lo largo de la historia política mapuche del siglo XX.

\section{Lo intraducible en Manuel Manquilef $y$ en Manuel Aburto Panguilef}

Una de las formas de traducción política de las o de la demanda mapuche a lo largo del siglo XX se dio a través de la representación parlamentaria. En este marco el proyecto del diputado mapuche Manuel Manquilef, diputado por el partido Liberal Democrático, puede ser entendido justamente como un proyecto liberal orientado a la plena traducción de lo mapuche a la ciudadanía chilena mediante su acceso pleno a la propiedad de la tierra. Tempranamente Manquilef expresaba esta voluntad de traducción plena cuando en 1915 escribía: "Esperamos que el Gobierno cambie de rumbos y que de una vez mate a los indios y los coloque en situación de vivir como los demás ciudadanos" (Manquilef 1915: 37). La muerte del indio propugnada por Manquilef es en realidad una muerte legal mediante la anulación de la intraductibilidad jurídica que implicaba el carácter colectivo e inajenable de la propiedad de los terrenos comunitarios según lo estipulaban las leyes de radicación. Es siguiendo este mismo criterio que en su propuesta de ley de división de las comunidades de 1926, y consciente de los peligros que implicaría un acceso universal de los mapuche a la propiedad individual y por lo tanto a la posibilidad de enajenación de sus tierras, Manquilef proponía un acceso escalonado a esta misma en función del nivel de "civilización", es decir de alfabetización de las personas. Para ello distinguía entre tres niveles: mapuche no civilizados, mapuche semi-civilizados y mapuche civilizados. De estos tres, sólo los últimos podrían acceder a la plena ciudadanía que les daría la propiedad privada de sus tierras y la libre disposición de las mismas, mientras que los dos primeros quedarían sometidos al régimen de protección que el estado de derecho reserva a los menores de edad, esperando de esta manera crear un estímulo hacia la educación. ${ }^{4}$ Pero lo interesante de su postura, es que a la hora de defenderla, no dudaba en recurrir a la figura más empleada en esa época para articular un intraducible político, la raza: "Mi sangre me dice que con este proyecto estoy sirviendo leal y efectivamente a la raza araucana". ${ }^{5}$

Así utilizada, la noción de raza funciona como un dato biológico, es decir pre-político, de argumentación política, un intraducible político que hace funcionar al servicio de la plena traducción política de los mapuche a la ciudadanía chilena. Lo interesante aquí, es que esta traducción política, no implica una desaparición de este resto racial y literalmente intraducible. Véase por ejemplo lo que Manquilef decía unos quince años antes como dirigente de la recientemente inaugurada Sociedad Caupolicán:

En una entrevista dada el año 1926, Manquilef decía que con su ley buscaba producir el "estímulo cultural indigena, es decir mediante este proyecto podrán tener libre disposicion sobre sus bienes solo los indios civilizados: los semi civilizados dispondrán de sus bienes en conformidad a la ley de menores de edad y los analfabetos seguiran bajo el imperio de las leyes prohibitivas que rigen hasta hoy desde 1866" (El Diario Austral, 11/09/1926). 
Aprovechando la oportunidad de tener aquí presente a los mas prestijiosos hijos de Arauco, voy a hablarles en el idioma de nuestros padres, porque solo esa lengua se presta con ventaja para comunicarnos las noticias y los pensamientos de nuestras jentes. Todos tenemos una misma sangre, una misma alma y un mismo corazón. De aquí, pues, que los pensamientos de cualquiera de nosotros sean considerados en conjunto como la idea de una raza. ${ }^{6}$

Lejos de desaparecer, el intraducible racial persiste, pero vuelto un resto inscrito en la interioridad corporal de los individuos, como un suplemento identitario, un patrimonio diríamos hoy día, pero debilitado en sus potencias de cuestionamiento del ordenamiento de lo público al quedar encapsulado en un espacio corporal y biológicamente privado. En coherencia con sus principios liberales, esta dimensión identitaria entrará en el mismo ámbito de lo privado que estos principios reservan por ejemplo a la dimensión religiosa respecto del espacio público, lo que en cierta forma prefigura la condición espiritual con que el actual modelo multicultural suele codificar las diferencias étnicas cuando se trata de pueblos indígenas.

En este mismo marco, elementos que hoy Ilamaríamos culturales, como la lengua, quedan confinados dentro de los márgenes de un espacio más estético que político, un espacio folklórico (que a su vez prefigura las actuales codificaciones patrimoniales de la diversidad étnica) circunscrito por un orden público, chileno y nacional, que lo contiene y en cierta forma lo dota de valor. Como lo he tratado en otro artículo (Menard, 2006), el formato de doble columna mapudungun-español al que recurre Manquilef en su escritura, puntualmente en sus Comentarios del pueblo araucano (1911-1914), constituye un formato en el que el discurso y texto en mapudungun aparecen sistemáticamente adosados y enmarcados por su traducción al castellano, lo que es coherente con su tratamiento de la identidad mapuche como una forma de suplemento identitario de carácter privado, por no buscar constituir un espacio lingüístico autónomo y soberano instalado en una relación de horizontalidad política respecto del espacio lingüístico chileno.

Esta relación con la lengua y la escritura mapuche, así como con el problema más general del lugar político de la traducción que en ella se refleja, se opone a otros proyectos políticos mapuche contemporáneos que consideraban explícitamente esta dimensión lingüística. $Y$ aquí pienso concretamente en el caso de la Federación Araucana, la que por ejemplo proponía en los acuerdos de su tercer congreso extraordinario en 1935 lo siguiente:

La construcción y sostenimiento por el estado de escuelas
Mapuches, donde éstos las soliciten, y entrega de ella a
su control y libre elección por ellos de los Profesores y
métodos de enseñanza. Declaración del idioma mapuche
como idioma oficial en sus reducciones, y en sus
relaciones con el estado y sus oficinas públicas, para lo
cual se elaborará un alfabeto mapuche, y se colocarán
empleados de la raza en todas las reparticiones públicas.

Esta demanda lingüística del año 1935 es coherente con el proyecto desarrollado a lo largo de su vida por Manuel Aburto, presidente vitalicio de dicha organización, proyecto doble que, por un lado, buscaba la constitución de un órgano de representación de la "raza araucana" ante el Estado y la sociedad chilena (la Federación Araucana y el Congreso Araucano), y por otro ejercer una forma de autonomía efectiva de carácter fundamentalmente jurídico. Esta propuesta generará así dos formas de

Federación Araucana 1935, "Acuerdos del tercer congreso extraordinario de la Federación araucana: temuco, 31 de mayo de 1935", Loncoche: Archivo Museo Municipal de Loncoche 
intraducible: por un lado, se introduce un intraducible político basado en un orden metafísico y espiritual que Manuel Aburto enarbolará como una forma de capital político exclusivamente mapuche. Se trata de aquellas "fuerzas" o "influencias espirituales de la raza", o en otros momentos "virtudes de la raza", de las que Manuel Aburto dispondrá, pudiendo ofrecerlas o retirarlas en el juego de sus alianzas y posicionamientos respecto del mundo político chileno. Es lo que ocurrirá por ejemplo cuando en 1931 la Federación Araucana llama a dirigir dichas fuerzas espirituales a favor del entonces candidato a la presidencia Arturo Alessandri Palma:

que todos los presidentes de los consejos federales y demás caciques adherentes a la Federación araucana, de las distintas regiones de la Araucanía deben tocar sus cornetas, cull-cull o trutrucas en la mañana del día 27 del presente mes de septiembre, día domingo rayando el sol, y a las diez de la misma mañana orar a Dios y nuestro señor Jesucristo, invocándose las virtudes propias de la raza para que sea Presidente de la república el señor Arturo Alessandri Palma, y para que su gobierno resuelva el problema de tierras cortando todas las injusticias, y educación de la raza araucana. La oración se hará con muday. ${ }^{8}$

Fuerzas que tras la represión de la que Manuel Aburto será objeto por el mismo Arturo Alessandri cinco años más tarde, serán a su vez retiradas:

$\left.3^{\circ}\right)$ acuerda exhortar a todos los caciques, representantes y hermanos adherentes a la Federación araucana y congreso araucano, en general, para que oren a Dios y al señor del actual, rayando el sol, con Mushay [bebida ritual] y «Fchotu» [inciensos rituales], para el pronto regreso del Presidente de la araucanía de su relegación, para su tranquilidad y bienestar, y para que actual Presidente de la república, Dn. Arturo Alessandri Palma, no se mantenga por más tiempo en el Poder de ser «Lonko» de la república por todas las persecuciones y relegaciones que ha hecho en la actualidad, 2 después de haber ofrecido a la raza

Aburto Panguilef, Manuel 1931, "Circular a todos los caciques", $E$ Diario Austral, 24/09/1931. araucana que les haría justicia y que todas sus peticiones serían atendidas una vez que llegara al Poder ...

En este movimiento de donaciones y retiros de fuerzas espirituales, lo que pareciera estar en juego es justamente el uso de una forma espiritualizada de lo intraducible como afirmación de una asimetría política y ontológica entre el espacio chileno y el mapuche, una en la que estos últimos gozarían de un acceso privilegiado a esa energética espiritual de la que la sociedad o al menos la política chilena carecería. Pero lo interesante es que la afirmación de esta asimetría espiritual, puede ser entendida como la puesta en escena de una simetría política en otro nivel, puesto que opone a las fuerzas militares y económicas efectivas que el Estado chileno ejerce y monopoliza, las fuerzas espirituales de las que sólo la raza mapuche -en virtud de su autoctonía- tendría el monopolio. ${ }^{10}$

Y por otro lado el proyecto de Aburto y la Federación Araucana introduce un intraducible jurídico, como base de su intento por ejercer una forma de autonomía mapuche de carácter judicial.

... en los últimos meses del año 1921 y con motivo de haber conocido en Santiago un proyecto de ley relacionado con los intereses materiales y estado sociológico de

Federación Araucana 1936, «Acuerdos de la sesión de 15 del presente mes, Temuco, 16 de marzo de 1936», Loncoche: Archivo Museo Municipal de Loncoche.

10 Esta convicción de la relación entre autoctonía y el privilegio espiritual de los mapuche por su cercanía a Dios es bien ilustrada por esta cita del guardián de la Piedra Santa de Lumaco referida por Helmut Schindler: "El Señor está muy, está más cerca de los Mapuches, por el Mapuche era el primer hombre que hizo. De ahí salió el resto [de la humanidad]. Mi finada abuelita decía, que el Señor hizo [al Mapuche de] una masa y después dijo: 'Te hice, tú eres la tierra que se llama mapu y te vas a llamar Mapuche. La tierra te va a criar y en la tierra te vas a terminar porque tú eres de la tierra'. Así es, le pegaron un soplido y salió la persona. Por eso es que el Señor está más del Mapuche ante que las otras razas porque fue el primer hombre que hizo" (Schindler, Helmut 2006: 29). 
la raza araucana, elaborado por cierto por una persona que no entiende ni puede entender la legislación natural de esta raza, tanto por su moral como por sus intereses materiales, en el mes de agosto de 1921 (...) manifesté al señor Montané, el actual inspector general de colonización e inmigración, que (...) sólo la voluntad soberana de la araucanía era la llamada para pedir las leyes que le convenían y nadie más" (mis cursivas). ${ }^{11}$

Como vemos, este intraducible jurídico adquiere la forma de una "legislación natural de la raza", legislación que basa parte de su intraductibilidad en el sustraerse -como veremos, paradójicamente- a la escritura:

"SOMOS UN GRAN PUEBLO, LA LEGISLACIÓN NO ESCRITA ES MÁS SABIA. SOMOS LA BASE DE UNA GRAN RAZA, COMO LO RECONOCE EL HIMNO NACIONAL, PUES EL ARAUCANO JAMÁS HA SIDO VENCIDO". ${ }^{12}$

Podría pensarse que esta oposición entre legislación natural de la raza y escritura constituye una prefiguración de las más recientes teorizaciones en torno al antagonismo entre culturales orales y culturas escritas, pero para Manuel Aburto la escritura no parece ser aun sinónimo de extrañeza absoluta, es decir ese fetiche de un intraducible winka u occidental correlativo de cierta noción de oralidad como fetiche de un intraducible indígena. De hecho, y como lo hemos visto en otros trabajos (Menard y Pavéz 2005), esta "legislación no escrita" producirá un enorme corpus de escritura, una verdadero archivo judicial nutrido de una creciente jurisprudencia mapuche..$^{13}$

Aburto Panguilef, Manuel 1923, "Los fines que persigue la Federación araucana de Loncoche (Collimalliñ)", El Mercurio, 20/01/1923.

12 La Nación 26/12/1924, mayúsculas en el original.

13 Véase por ejemplo Aburto Panguilef, M. 1928. "Reclamo no 355 de don celestino Quileñan y de su esposa doña Anjelina Meliñanco Reumai.- sobre cuentos propios entre la raza araucana, o más bien dicho, hechicerías: Temuco, octubre de 1928", Santiago de Chile: Archivo Nacional de la Administración, Fondo Ministerio del Interior. Vol. 7321, Archivo C.L.S. Providencia 1556.
En esos otros trabajos ya citados, hemos visto cómo en Aburto la noción de raza no remite (solamente) al dato biológico y pre-político del que Manuel Manquilef se servía para sostener sus propuestas políticas, sino que en cierta forma funcionaba como una suerte de efecto político inseparable del trabajo de escritura y de la consecuente producción de un archivo propio en la que se materializaba. En este sentido, es importante recordar que Manuel Aburto llamaba a los mapuche a no recurrir a los tribunales chilenos para zanjar sus conflictos entre ellos ni con los chilenos, postura correlativa de su llamado a no inscribir nacimientos, matrimonios ni defunciones en los archivos chilenos sino que en los archivos de la Federación Araucana. Y esto puede explicarse en la medida en que este trabajo jurídico requería a su vez de la formación de una suerte de registro civil mapuche por el que esta raza asumía una forma políticamente concreta y sobre la cual podía ejercerse la autonomía jurídica buscada.

Ahora, si nos detenemos en el problema lingüístico respecto del lugar que el mapudungun ocupa en los textos de Manuel Aburto, vemos que este aparece principalmente en dos contextos: o cuando transcribe un diálogo o el fragmento de algún diálogo con algún interlocutor mapuche, o en oraciones que él dirige o en mensajes espirituales que recibe. Contra la lógica de la doble columna que vimos para el caso de Manquilef, donde el mapudungun queda sistemáticamente circunscrito en y por un archivo chileno y en castellano, en el caso de Aburto constatamos que la escritura en mapudungun no busca marcar los vestigios más o menos folklóricos de una mapuchidad más o menos traducible, en la medida en que ya está escribiendo en un archivo que, más que cultural, lingüística o biológicamente mapuche, se considera políticamente mapuche. 
Por otra parte, la escritura a doble columna de Manquilef es coherente con el hecho de que tras la conquista militar y la pérdida de una autonomía territorial mapuche, es decir, con la pérdida de una frontera territorial como marcador de lo mapuche, la idea o función de frontera pasó del territorio a los individuos, y más precisamente a sus cuerpos, los que se constituyeron en soportes de una marca o suplemento de mapuchidad (codificado en términos de raza, lengua, religión o cultura) inscrito en y sancionado por los archivos poblacionales, históricos, jurídicos, económicos, etc., chilenos. Por el contrario, el proyecto de Aburto y la Federación Araucana puede entenderse como un intento por asegurar la continuidad -o como veremos un simulacro de continuidad- de la autonomía política y territorial perdida, para que de esta forma lo mapuche ya no fuera necesariamente significado en función de su inscripción en los archivos chilenos, sino se expresara como efecto de la afirmación de una diferencia política entre dos archivos o aparatos de archivación: el mapuche y el chileno.

\section{Lo intraducible entre Venancio Coñuepan y la década de los setenta.}

Hasta cierto punto, tanto la dimensión autonómica del proyecto aburtiano (en el que el intraducible mapuche fue traducido -desde 1932- mediante la propuesta de una república indígena federada a Chile), como el proyecto manquilefiano de plena traductibilidad liberal de lo mapuche al régimen ciudadano y de propiedad chilena fracasaron, al menos, como proyectos de Estado. Más éxito tuvo Venancio Coñuepan, quien en el año 1952 logra acceder al Estado como ministro de tierras y colonización del gobierno de Ibáñez del Campo y fundar desde allí la Dirección de Asuntos Indígenas (DASIN), la que puede ser entendida como un dispositivo de salvaguarda de la especificidad mapuche dentro del Estado.

Desde allí Coñuepan sostendrá el intraducible mapuche en dos niveles: nuevamente uno jurídico, pero también uno territorial basado en la defensa de la comunidad frente a los sucesivos intentos legislativos por dividirla, y otro de corte más estético o performático (que en parte remite a una dimensión de exhibición ritual y costumbrista inaugurada por el mismo Aburto con la creación de conjuntos artísticos mapuche desde 1910) consistente en la puesta en escena de unas costumbres, pero también de unos cuerpos irreductiblemente mapuche, como podemos ver en la siguiente descripción de un desfile organizado por la Corporación Araucana en 1953:

\footnotetext{
Luego seguirá un letrero que llevará la siguiente leyenda: "Máxima aspiración de una raza fuerte dentro de un Chile grande". A continuación irán 12 hermosas indias formando un bosque de banderas chilenas.

Posteriormente prosiguiendo el desfilo, seguirá un equipo listo para entrar en juego de CHUECA, con todos sus objetos necesarios para un partido. Después continuarán un grupo MACHIS, con sus cultrunes. Seguirán un grupo de indios y posteriormente otro tocando los diversos instrumentos como son trutrucas, cullcull. Lolquín, pifilca y otros que le darán más emotividad a este acto. ${ }^{14}$
}

Costumbres y cuerpos irreductiblemente mapuche, pero exhibidos y puestos en valor como miembros del cuerpo mayor de la nación, propuesta coherente con las doctrinas corporativistas que guiaban el gobierno del propio lbáñez del Campo.

Pero el proyecto de Coñuepan estaba tensionado por dos fenómenos históricos: por

El Diario Austral 12/12/1953 
un lado, el surgimiento de una nueva generación de dirigentes mapuche aliados a los partidos políticos chilenos de izquierda y más tarde al horizonte de la reforma agraria. De esta forma y en un movimiento prefigurado en parte por la creación en 1937 del Frente Único Araucano aliado al Frente Popular, y más claramente por la creación de la Asociación Nacional de Indígenas (ANI) en 1952, la demanda mapuche comenzó a ser traducida en los códigos de una demanda de clase y campesina. Y por otro lado se debe considerar la crisis, acaecida tras la II Guerra Mundial de la noción de raza como dispositivo articulador de diferencias e intraducibles entre los grupos humanos. De hecho, se puede ilustrar el peso de esta crisis del racialismo en la crítica que por ejemplo Martín Painemal, miembro del Partido Comunista y fundador de la $\mathrm{ANI}$, le hace a Coñuepan de quien dice que "propagaba mucho la cuestión del racismo, porque así ganaba simpatía para ser candidato. Nosotros decíamos que no había por qué estar aparte, que había que unirse fraternalmente con la clase obrera". ${ }^{15}$

Es en esa época que la raza como término articulador del intraducible mapuche comienza a ser reemplazado por otros términos, particularmente el de cultura, el que, sin embargo, oscilará a su vez entre su sentido humanista y su sentido antropológico y relativista. De hecho, durante la década de los cincuenta vemos cómo el uso del término cultura suele significar más bien el primer sentido, que la hace funcionar como el marco universal de acumulación de un capital de lo que cierto canon occidental define como "culto" o civilizado o en otras palabras como

Foerster, Rolf 1983, Martín Segundo Painemal. Vida de un dirigente mapuche, Santiago: GIA y Academia de Humanismo Cristiano, p. 80. un dispositivo de traducción de las diferencias enmarcadas en un esquema de ordenamiento evolucionista de las mismas. Este sentido unívoco de la cultura es el que, por ejemplo, le permitía a Rodolfo Lenz a principios del siglo XX entender el problema de la traducción como un problema de irreversibilidad evolutiva entre lo concreto y lo abstracto:

\begin{abstract}
... se nota una diferencia importante según estamos bajando o subiendo en la cultura. Así como en la misma lengua culta el sabio, digamos el profesor de filosofía, comprende perfectamente el balbuceo de su hijo, de dos o tres años de edad, pero éste no comprende nada de un discurso académico de su padre, así es posible espresar i aun imitar en forma mas o ménos parecida en el idioma culto moderno, todas las formas cultas antiguas i las incultas modernas; pero nó al reves. (Lenz 1910: 243)
\end{abstract}

De esta forma Lenz subordina el intraducible mapuche a la potencia omnitraductiva de esa Cultura con mayúscula que terminaría por englobarlo. ${ }^{16}$

En este sentido es interesante constatar la persistencia de esta noción humanista de cultura en los años cincuenta justamente cuando se le introduce como una variable pertinente en el ámbito jurídico, como lo ilustra el caso del juicio contra Juana Catrilaf acusada de asesinar a su abuela por considerarla bruja. La defensa recurrirá a un intraducible jurídico que, si bien prefigura ciertas formas del relativismo jurídico posterior, aun comprende la dimensión cultural en términos de una carencia, en lugar de la cultura como indicador de un intraducible radical:

Nos permitimos agregar que la responsabilidad por el acto perpetrado por la reo, es únicamente nuestra, es decir de nuestra sociedad, la cual, a través de tantos años ha continuado y continua manteniendo a diversos núcleos de indígenas en abandono cultural completo.

Para un análisis de esta comprensión evolucionista de la traducción en Lenz, cf. Menard (2006). 
El perito en pedagogía designado, profesor Liborio Acosta, informa que la reo es analfabeta y su nivel cultural muy bajo; que tiene ciertos conceptos elementales sobre las normas de vida civilizada como respecto a las autoridades, pero que todos estos conceptos han sido supeditados con la influencia poderosísima de sus costumbres y supersticiones. ${ }^{17}$

El intraducible cultural es traducido bajo la figura de "costumbres y supersticiones" derivadas de una "abandono cultural completo", lo que implica un lamento por la carencia de cultura que va a comenzar a ser paulatinamente reemplazado por un lamento nuevo, el lamento por la creciente carencia de "diversidad cultural" que por ejemplo levantará LéviStrauss por esos años (1952: 496), lamento que alcanzará su institucionalización UNESCiana y patrimonializante recién a fines del siglo XX.

Otro ejemplo ilustrativo de esta oscilación de los sentidos del término cultura en su proceso de reemplazo de la terminología racial, es el que ofrece la declaración de principios de la ANI al momento de su fundación en 1953:

La Asociación Nacional Indígena de Chile trabajará por organizar en una sola Central a todos los mapuches del país, a fin de lograr su completa emancipación en su calidad de Minoría Nacional, luchará por abolir toda forma de discriminación racial; por la conservación de su cultura, de su lengua y de su arte, y por la reconquista de sus tierras; luchará por elevar el nivel económico, político, social y cultural de los asociados. (citado en Foerster y Painemal 1983: 79).

Junto a la ya señalada crítica al racismo de Coñuepan, vemos en esta declaración cómo la cultura, entendida como una cultura específicamente mapuche, es reivindicada en tanto objeto -intraducible- de conservación, y

Corte de Valdivia 1953, “Jurisprudencia sección cuarta jurisdicción criminal. Corte de Valdivia, 7 de diciembre de 1953. Contra Juana Catrilaf", en Revista de Derecho y Jurisprudencia, de Santiago de Chile, t. LII, julio y agosto de 1955, números 5 y 6, pp. 85-102 al mismo tiempo como un objeto de demanda traducible en términos de nivel, es decir de carencia y eventual acumulación.

Habrá que esperar hasta la década del setenta para que comience a tomar forma una nueva demanda indígena en general y mapuche en particular basada en el concepto relativista y no humanista de cultura, la que derivará en las formulaciones multi e interculturales de los años ochenta y que hegemonizarán las políticas indígenas a partir de los noventa.

Un hito clave en este proceso histórico lo constituye la aparición de un nuevo término, el de cosmovisión, término que irrumpe en el corpus mapuchográfico justamente en el momento quizás culminante de la traducción clasista y campesina de la demanda mapuche, con la publicación en 1972 del famoso artículo de la antropóloga Maria Ester Grebe y sus colaboradores "Cosmovisión mapuche" (1972). Así en pleno proceso de reforma agraria Grebe escribe:

El carácter sagrado de la tierra y la relación telúrica y etnocéntrica del mapuche con respecto a la misma contribuye a erigir una de las principales barreras culturales que deben enfrentar los técnicos. Dichos obstáculos pueden ser controlados, con mayor propiedad por medio del conocimiento acerca de la cosmovisión mapuche, cuna de muchas normas, actitudes y valores de su cultura. (Grebe et al. 1972: 72-73). ${ }^{18}$

La cosmovisión, planteada como núcleo distintivo anterior incluso a la cultura, se transforma así en el nuevo nombre del intraducible, un intraducible que viene a interrumpir la hasta ese momento hegemónica traducción política y técnico-económica de

\footnotetext{
Para una interesante investigación en torno a las bambalinas etnográficas que subyacen a la instalación de este concepto en la obra de Maria Ester Grebe ver González Dinamarca (2018).
} 
lo mapuche. Se estructura así un esquema en el que las dinámicas políticas e históricas contingentes se opondrían a una forma de ver el mundo ancestral y en consecuencia ahistórica. Es en este marco que en los años posteriores adquirirá relevancia la oposición correlativa entre oralidad y escritura como forma privilegiada de codificar la intraductibilidad mapuche en términos culturales o cosmovisionales. En el apartado siguiente analizaremos las formas en que esta oposición entre oralidad y escritura determinó el trabajo de dos intelectuales mapuche, Martín Alonqueo y Anselmo Raguileo, y en los que la pregunta por la in/traductibilidad mapuche se expresó justamente en el problema de la escritura de un habla mapuche, o más precisamente, de la definición de su correcta trascripción grafemática.

\section{Lo intraducible en Martín Alonqueo y en Anselmo Raguileo}

El año 1979 el profesor Martín Alonqueo publica el libro Instituciones religiosas del pueblo mapuche. Este libro junto con su obra póstuma El habla de mi tierra (Alonqueo 1989) publicada diez años más tarde, enmarcan el proyecto intelectual de Alonqueo en lo que podría definirse como un proyecto de doble traducción del intraducible mapuche, traducción teológica en un caso -de la religión mapuche al catolicismoy de traducción lingüística en el otro. Al leer el primer libro llama la atención la forma en que Alonqueo no sólo traduce, sino que también transcribe las oraciones de ngillatun así como los cantos de machi que recopila y que presenta según el tradicional formato de doble columna mapudungun/castellano. Como lo he analizado en otros artículos (Menard 2004), resulta llamativo en primer lugar la asimetría entre la brevedad de los párrafos en mapudungun y la extensión que alcanzan en su traducción al castellano (ver imagen 1).

Imagen 1. canto de machi transcrito y traducido por Martín Alonqueo, año 1979.

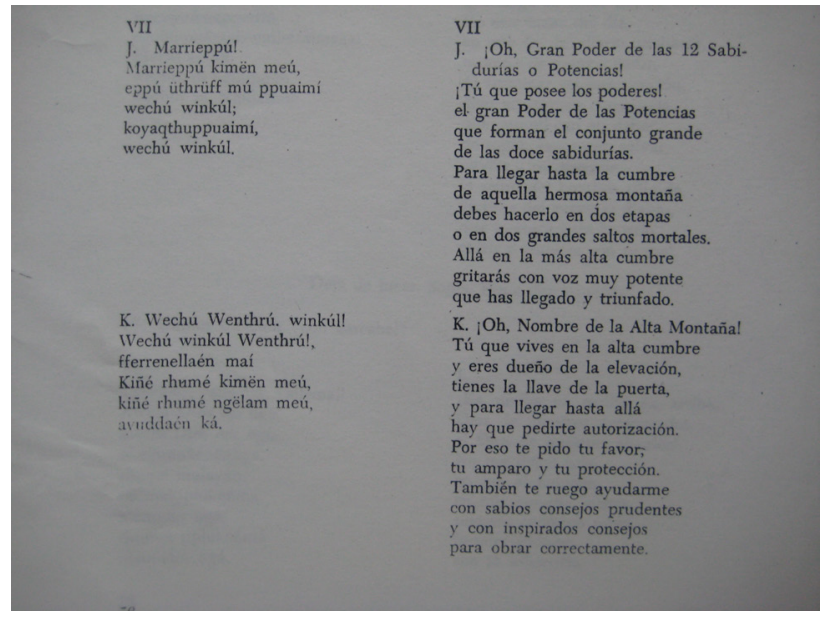

Fuente: Martín Alonqueo 1979, Instituciones religiosas del pueblo mapuche, Santiago de Chile, Nueva Universidad, p. 76.

Al leer esas columna uno tiene la impresión de que Alonqueo no sólo está poniendo en escena la intraductibilidad de unos contenidos en mapudungun mediante la multiplicación de palabras en castellano por la que intenta desplegar -pero mostrando en el mismo gesto la imposibilidad de ese despliegue- la irreductible densidad de su sentido, sino que también está poniendo en escena la intranscriptibilidad de la palabra mapuche mediante la multiplicación de letras o grafemas, más específicamente de ciertas consonantes sin valor fonológico.

En un manuscrito inédito Alonqueo explicitaba esta opción grafemática de la siguiente forma: 
1-La fonética, en general, es el estudio de la voz en su aspecto físico fisiológico del lenguaje humano, estableciendo normas precisas de la pronunciación de los sonidos de cada fonema.

2- La fonética mapuche. La fonética mapuche sigue la misma norma, porque no es una raza extra-mundo, sino que es miembro vivo de la especie del "Homo Sapiens" pero sí con su característica peculiar como una raza: es gutural y ronca y así genera la voz.

3-Hoy día, el pueblo mapuche que aun habla su Idioma, no lo habla bien por el sistema imperante que es excluyente, absorbente y dominante que va destruyendo la psicología mapuche, la idiosincrasia, su manera de ser y pensar. De esta manera se destruye la mentalidad mapuche, porque el nuevo ambiente le es adverso y difícil. ${ }^{19}$

Vemos cómo el intraducible aparece como esa característica racialmente "peculiar" materializada en la presencia de una voz irreductible a la plena traducción biológica y humanista de la diferencia mapuche dentro de los marcos de la especie. Así el peligro de destrucción cultural, o en sus términos, de destrucción idiosincrática de esa especificidad mental mapuche, parece inseparable del deterioro de la correcta articulación de su idioma.

Lo interesante en Alonqueo, es que al intentar transcribir la irreductible especificidad que emanaría de la presencia oral y por tanto corporal deun hablanteauténticamentemapuche, termina multiplicando esas letras supernumerarias, esas consonantes desprovistas de valor fonológico, y de esta forma deriva en la paradoja de que la única forma de transcribir la intranscriptible presencia del hablante en su oralidad, es mediante la proliferación de una escritura (las consonantes sin valor fonológico) despegada del habla como vehículo de un sentido. Lo intraducible se encarna así en esas consonantes duplicadas, intraducible cultural pero que, al aparecer indisolublemente asociado a la irreductible presencia de un hablante, hace entrar nuevamente al cuerpo como ese espacio de lo intraducible que en su momento vehiculó la noción de raza. Esto, por lo demás, es coherente con la convicción antropológica contemporánea en la consistencia inmaterial de unas culturas o de unas cosmovisiones entendidas como la forma privilegiada del patrimonio cultural entre los "pueblos sin escritura" o "de tradición oral", lo que implica la necesidad de contar con un tipo específico de sujeto, un sujeto capaz de acceder inmediatamente a estos contenidos culturales que, al ser de naturaleza oral, requieren de la presencia corporal, y por lo tanto cripto-racial, de aquel que la antropología ha investido en el rol del "informante".

Otro era el proyecto de Anselmo Raguileo, químico y militante comunista, quien a mediados de los ochenta desarrolló un grafemario mapuche que hasta el día de hoy ostenta cierta aura de radicalidad política del que carecen las numerosas otras propuestas grafemáticas. ¿Pero en qué se basa esta aura de radicalidad? La respuesta quizás tenga que ver con la buscada distancia que su grafemario establece respecto de una correlación inmediata o incluso intuitiva con la función de las letras en el alfabeto castellano. Para entenderlo comparemos primero el alfabeto unificado -sancionado en 1986- y el Raguileo: 
Tabla 1. El grafemario unificado comparado con el grafemario Raguileo

\begin{tabular}{|c|c|}
\hline Unificado & Raguileo \\
\hline $\mathrm{ch}$ & c \\
\hline$d$ & $z$ \\
\hline$f$ & $f$ \\
\hline g & q \\
\hline $\mathrm{k}$ & $\mathrm{k}$ \\
\hline I & I \\
\hline$\|$ & $\mathrm{j}$ \\
\hline $\mathrm{m}$ & $\mathrm{m}$ \\
\hline $\mathrm{n}$ & $\mathrm{n}$ \\
\hline$\tilde{n}$ & $\tilde{n}$ \\
\hline$p$ & $p$ \\
\hline$r$ & $r$ \\
\hline $\mathrm{s}$ & $\mathrm{s}$ \\
\hline $\mathrm{t}$ & $\mathrm{t}$ \\
\hline w & w \\
\hline$y$ & $y$ \\
\hline$\underline{1}$ & b \\
\hline$\underline{\mathrm{n}}$ & $\mathrm{h}$ \\
\hline $\mathrm{ng}$ & g \\
\hline $\operatorname{tr}$ & $x$ \\
\hline$\underline{t}$ & \\
\hline
\end{tabular}

Fuente: Tabla parcialmente extraída de Clavería (2015): 78.

Resalta en esta comparación la distancia funcional de ciertas letras respecto de su uso en castellano, como en los valores que adquieren letras como la "c", la "j", la "b" o la "x".

La explicación de esta discordancia tiene que ver con la lógica que Raguileo empleó para dotar a la lengua mapuche de un alfabeto que permitiera una transcripción de sus palabras que a su manera no dejara de afirmar la marca de un intraducible. Pero si en el caso de Alonqueo esta se fundamentaba en criterios teológicos y raciales, en el caso de Raguileo lo hará en función de criterios técnicos y explícitamente políticos.

Sabemos por los testimonios de sus contemporáneos que el proyecto ideal para Raguileo hubiera sido el contar con un alfabeto estrictamente mapuche, es decir uno provisto de signos exclusivos para esta lengua. Es lo que su hija, Ruby Raguileo le contara al antropólogo Alejandro Clavería:

\footnotetext{
...es que mi papá decía que él podía haber ideado digamos, unos dibujitos distintos, que fueran como más autóctonos, más propios del pueblo mapuche, pero que lamentablemente ya en ese tiempo estaba la máquina de escribir, los tipógrafos ya estaban todos con un sistema de escritura, entonces teníamos que usar eso en beneficio nuestro, porque si no tendríamos que haber tenido nuestras propias máquinas de escribir, nuestros propios tipógrafos, y ¡de dónde!, si nunca hemos tenido dinero. Era imposible. Entonces, era darle un uso distinto nomás. (Clavería 2015: 50)
}

El proyecto ideal es así adecuado a unas condiciones técnicas y materiales concretas mediante la siguiente lógica. En primer lugar, Raguileo constata la presencia de sonidos compartidos por el castellano y el mapudungun. Para ellos mantendrá las mismas letras en ambos alfabetos. En segundo lugar, constata la presencia de sonidos del castellano inexistentes en mapudungun e inversamente de sonidos del mapudungun inexistentes en el castellano, de esta forma elegirá más o menos arbitrariamente las letras correspondientes a los primeros (los sonidos inexistentes en mapudungun) para adjudicárselas a los segundos (los sonidos inexistentes en castellano). De ahí la presencia de esa " $x$ " $y$ de esa "b" para transcribir sonidos 
que el alfabeto unificado transcribe con los grafemas "tr" o "l”".

De esta forma Raguileo articulaba una determinante técnica, la existencia de la máquina de escribir, con una convicción plenamente política: la de recurrir al alfabeto winka, pero afirmando justamente en la arbitrariedad de esas letras incongruentes, la fuerza de una decisión que podríamos llamar soberana. Esto queda claro en este otro testimonio recabado por Clavería, uno en el que Mireya Zambrano le explica cómo "Anselmo lo metió con mucha fuerza, esto de que ellos [los mapuche] tenían el derecho a poner los signos que se les ocurriera para los sonidos que ellos hacían al hablar. Que ellos tenían pleno derecho, que no tenían por qué parecerse al español, ni parecerse a nada" (Clavería 2015: 50).

Es en este marco que según otro testimonio (el de Ernesto Huenchulaf) Raguileo consideraba que "para escribir en mapudungun hay que pedir ropa prestada" (Clavería 2015: 51). Y como vimos era justamente lo que hacía en su grafemario tomando "prestadas" esas letras del castellano, las que por su distancia fonética respecto de los sonidos del mapudungun que debían representar, tenían el efecto añadido de enfatizar aún más su condición de "prestadas". De esta forma, y a diferencia de esa fenomenología de la presencia que orientaba las transcripciones de Alonqueo, en Raguileo sobresale el énfasis puesto en la visibilización de ese momento soberano, del arbitrario político de la decisión alfabética, decisión que se oponía a la idea del grafemario como efecto de una más negociada y más técnica "convención". En palabras de Clavería: "A través de este movimiento Raguileo desnudó a la convención, la despojó de sus harapos técnicos, de sus músculos técnicos y la dejó en sus huesos relucientes de una realidad más profunda: como un momento y un espacio de poder. La convención es siempre política" (Clavería 2015: 181).

Pero lo interesante aquí es que este desnudamiento de los vestido técnicos de la convención para develar así su fondo eminentemente político y decisional pasa por develar no la irrepresentable desnudez de un intraducible mapuche, sino que otros vestidos, la inefable extrañeza de una ropa prestada.

\section{Traducción y simulacro}

Esa notable imagen de la "ropa prestada" nos lleva al problema del disfraz, en este caso al de palabras mapuche disfrazadas de letras winka, lo que nos permite volver a la pregunta del inicio en torno a la relación entre traducción y simulacro. Para ello recurriré a la siguiente noticia publicada en el Diario Austral en marzo de 1962:

Sábado al medio día por personal del Servicio de Investigaciones al frente del jefe de la unidad, comisario don Luis Morales Parra, Manuel Norín Huaiquipán, de 29 años, alias "La Machi” o "Manuela Norín."

\footnotetext{
La policía el día indicado irrumpió violentamente en la ruca de Ignacia Ancamilla Collin, en la reducción indígena "Huequén", ubicada en los alrededores del pueblo del mismo nombre. La llegada de los detectives puso término al acto denominado "Machitún" y en el cual la anciana de 80 años María Dolores Ancamilla Luipal, era "tratada" por Manuela Norín que para dar mayor énfasis tocaba rítmicamente el "cultrún" hasta llegar a una especie de frenesí.
}

Los funcionarios policiales procedieron a requisar todo el "gabinete" de trabajo del pseudo médico que había cobrado la suma de $\mathrm{E}^{\circ} 4$, por curaciones y que consistía en el "cultrún", palillos, hierbas y un tiesto con un líquido negro. Una vez que las cosas se pusieron en claro, quedó en evidencia que Manuela Norín era un hombre que se 
disfrazaba de mujer para lograr mejores efectos entre los crédulos mapuches.

Todos los antecedentes de este singular caso fueron puestos en conocimiento de la justicia ordinaria el lunes en la mañana. Un grupo de indígenas concurrió ese día para pedir que el intendente don Carlos Jarpa intercediera ante la justicia y quedara libre "La Machi". ${ }^{20}$

Lo que me interesa relevar aquí es el uso que en la nota se hace de las comillas. Por un lado, estas sirven para indicar el origen o la naturaleza heterogénea de una palabra o una proposición sacada de su contexto de enunciación primario. Es por ejemplo lo que las comillas hacen en las citas de autoridad. Pero también para indicar el heterogéneo intraducible de una palabra respecto de una lengua o-como veremos- de un archivo propio, como en los casos del "cultrún", el "machitún" o el topónimo "Huequén" en la nota. Pero, por otro lado, las comillas también pueden funcionar como una forma de traducción de un término heterogéneo, pero sin dejar de indicar la condición de simulacro o incluso de impostura que implicaría su traducción llana y sin comillas, como en los casos de las comillas sobre "tratamiento" o "gabinete" que en la nota cumplen la misma función que el prefijo "pseudo" aplicado a la condición de doctor de la machi, prefijo que equivale a tratarla como un "doctor" entre comillas. $Y$ es con este mismo sentido que figuran las comillas sobre el nombre "Manuela Norín", comillas que significan algo como un alias y de esta forma están marcando su impropiedad respecto de la identidad civil y sexualmente verdadera de un Manuel Norín sin comillas. De esta forma la puesta entre comillas puede indicar una traducción y al mismo tiempo su descalificación denunciando su condición de simulacro, lo que de paso naturaliza el archivo exterior a las comillas, el archivo oficial del

(Diario Austral 1962.- "Acusada de ejercicio ilegal de la profesión fue detenida una 'machi'”, 17/03/1962) registro civil o judicial chileno, por ejemplo, por el cual la machi sería en realidad un hombre llamado Manuel Norín.

A partir de la noción de archivo que aquí he introducido se puede decir que el efecto político de esas comillas tiene que ver con las formas en que determinados archivos se imponen y hacen efectivas, naturalizándolas, ciertas formas de identificación. En este marco se entiende la densidad política del proyecto de Aburto y la Federación Araucana en su intento de constituir un archivo mapuche autónomo respecto de los archivos chilenos, un archivo en continuidad con aquellos construidos por los longko y sus secretarios en el siglo XIX..$^{21}$ Pero en la medida en que estos archivos por un lado no se limitaban solamente a la inscripción de registros alfabéticos, sino que incluían otras formas del registro como nombres propios, piedras mágicas o casacas militares, y por otro lado, sobre todo en el contexto post-conquista militar, que es el contexto de Aburto, no disponían del capital de violencia coercitiva necesaria a la efectuación de sus mandatos archivísticos, ${ }^{22}$ quizás habría que hablar con más propiedad de unos "archivos" mapuche, de unos archivos entre comillas. Y aquí las comillas estarían funcionando nuevamente como en el caso del "gabinete" o del "tratamiento" de la Machi Norin, es decir, como traducciones que no sólo explicitan su imprecisión, sino también esa suerte de impostura que implica el vestirse con ropa prestada.

$21 \quad$ Para un mayor desarrollo de esta conceptualización del archivo y de la oposición entre un archivo mapuche y uno estatal o republicano, ver Menard (2013: xxiv y ss.).

22 Sobre la relativa impotencia de las decisiones jurídicas o políticas sancionadas en los archivos de la Federación Araucana y su doble limitación tanto por la falta de un poder coercitivo propio que las sostuviera como por el no reconocimiento, e incluso la persecución, de las que eran objeto por parte del Estado, ver Menard (2013: xxxii) 
Escribir "archivo" mapuche puede entenderse así como un vestir la afirmación de una forma de soberanía mapuche, o al menos de su búsqueda, con un significante winka. Esta operación recuerda el uso de esos uniformes militares chilenos y argentinos por los grandes longko del siglo XIX, los que al "disfrazarse" de coroneles o generales no sólo lograban afirmar la simetría política de su relación con los poderes políticos y militares winka, sino que por el mismo gesto lograban poner la condición naturalmente generalicia del general winka entre comillas. Así tanto en el caso de las comillas sobre el "archivo" de la Federación Araucana, como en el de las comillas sobre la condición generalicia de por ejemplo el longko Mangil Wenu vistiendo la casaca militar que le obsequiara el general Cruz, o incluso en el caso de las comillas sobre la condición de "mujer" de la machi Manuela Norín, puede decirse que en lugar de denunciar negativamente la falsedad del simulacro, lo que hacen es relevar su potencia afirmativa por la cual ponen en suspenso la naturalización de las políticas que está determinando todo aquello que queda antes y después de ellas. Así entendidas, las comillas derraman su poder de desnaturalización de los órdenes develando su propia condición de simulacro, es decir su condición histórica y políticamente contingente. El simulacro puede así ser entendido como una forma de traducción que justamente interrumpe la jerarquía entre original y simulacro.

Esta concepción afirmativa del simulacro nos remite a la pregunta del inicio en torno a las formas de comprender algo como la descolonización más allá de la reivindicación de unas formas supuestamente no occidentales o más autóctonas de jerarquizar y distinguir entre sentidos propios $u$ originarios y sus formas impropias, es decir sus simulacros, en la medida en que la dimensión colonial pareciera tener que ver más con estas formas de distinción y jerarquización entre dos niveles de sentido (propios y figurados, originales y simulados) que con la procedencia cultural de los contenidos así ordenados.

Como lo adelanté, en la última década del siglo XX el movimiento mapuche vuelve a reivindicar un intraducible respecto de las codificaciones partidistas chilenas, retomando en cierta forma el gesto que en la primera mitad del siglo postulaba ese intraducible espiritual que como vimos la Federación Araucana podía ofrecer o retirar a ciertos candidatos a la presidencia, y que en otros casos hacía posible que esta misma organización por ejemplo conminara al diputado mapuche por el Partido Democrático, Arturo Huenchullán a "que en los sucesivo se acerque más a las virtudes de la raza para sus actuaciones políticas, antes que hacerlo por el Partido Demócrata [...] porque se sabe que será un gran hombre y necesita marchar de acuerdo con su raza para que no carezca de influencias espirituales" (Citado en Foerster y Montecino 1988: 142). Pero como vimos, la asimetría política que instala este intraducible espiritual sirvió en su momento a la afirmación de una simetría política en otro nivel, aquella que oponía a los dispositivos de poder militar y económico monopolizados por Estado chileno un poder espiritual monopolizado por la raza mapuche.

Este juego entre simetría y asimetría política, juego correlativo a las posibilidades e imposibilidades de la traducción de unas demandas mapuche, persiste en el gesto análogo desarrollado desde principios de los noventa por el Consejo de Todas las Tierras y radicalizado por organizaciones posteriores 
como la Coordinadora Arauco Malleco (la que no sólo reafirmará esta distancia respecto de los partidos y aparatos de representación chilenos, sino que en un gesto más históricamente inédito, dejará de considerar al Estado como un interlocutor válido para sus demandas). Sin embargo, esta ambivalencia en las posiciones de enuncación se dará en un contexto diferente, uno en que las demandas de simetría política expresadas por ejemplo en las nociones de autonomía territorial, autogobierno o autodeterminación conviven con el estatus asimétrico que los nuevos ordenamientos globales y multiculturales reservan a los pueblos indígenas como categoría global, es decir como categoría genérica portadora de derechos específicos, por ejemplo espirituales, que los Estados se comprometen a respetar ante la comunidad internacional. Lo interesante es que la continuación de este gesto en este nuevo contexto por parte de estas organizaciones, irá acompañado de la ya señalada reivindicación de categorías autóctonas como las de werken o weichafe para señalar la intraducibilidad de su accionar político. Como ya lo adelanté al inicio, el problema es que, al utilizar estas categorías en un nuevo contexto histórico, sus sentidos adquieren inevitablemente nuevos atributos que las alejan de cualquier sentido supuestamente originario. En esta misma línea, y hablando del proyecto del Consejo de Todas las Tierras, José Ancan escribe:

Estas autoridades e instituciones tradicionales fueron en mayor o menor medida resignificadas en este proceso de convergencia, como ocurrió con el werken, que pasó de ser un mensajero sin influencia en los contenidos de los mensajes entre los longko a convertirse en dirigentevocero de los planteamientos de la organización (Ancan 2017: 292, nota 9).

El werken así entendido operaría un doble desplazamiento de su sentido, pues traiciona por un lado el sentido "original" de ser un simple transmisor de mensajes y decisiones derivadas de las autoridades tradicionales al convertirse en la forma visible de la dirigencia mapuche efectiva (capaz no sólo de influenciar sino que de producir contenidos políticos), y por otro interrumpe su posible traducción inmediata bajo la forma castellana del dirigente, el portavoz o incluso del presidente de una organización, marcando con el término mapuche werken su especificidad cultural, la que de paso lo vincula a la ya referida figura antropológica del informante en tanto sujeto transmisor de contenidos culturales colectivos, y que en su caso son materializados en la idea de esa masa anónima de longko o machi a los que el werken estaría supuestamente representando.

Algo similar puede decirse del término weichafe en su uso por parte de dirigentes de la Coordinadora Arauco Malleco. En su entrevista con Jorge Arrate, el líder de esta organización, Héctor Llaitul, definía al weichafe de la siguiente forma: "El weichafe que reaparece con fuerza es, en las actuales circunstancias, antes que nada, un luchador social, un transmisor de ideas, un militante; en pocas palabras, un dirigente apto para valerse de diversas formas de lucha". Pero justo antes, esta traducción más o menos directa del weichafe (es decir del guerrero mapuche) por términos como militante o dirigente, era interrumpida por la afirmación de una intraductibilidad cultural y espiritual: "No estamos organizando una guerra en el sentido común y corriente de esa palabra, o con la perspectiva convencional occidental. La nuestra es también una confrontación cultural y espiritual" (Llaitul y Arrate 2012: 25). De esta forma vemos cómo estos términos no sólo adquieren nuevos sentidos en función del nuevo contexto histórico y político en que se inscriben, sino que lo hacen 
también, y sobre todo, por el hecho de funcionar además como significantes de un espacio intermedio (llámese intercultural, interétnico o internacional) que los vuelve significantes de un mandato de traducción y por lo tanto de la persistencia de un intraducible, que en función de este mismo contexto, suele ser codificado en términos culturales y sobre todo espirituales.

Pero como ya lo anuncié, la reivindicación de estas formas auténticamente, esto es intraduciblemente mapuche de la política (formas fundadas en un supuesto núcleo cultural o espiritual que trasciende la historia), termina finalmente encontrando una estructura argumental que podemos llamar colonial, pues no difiere de aquella con que el Estado se permiten deslegitimar ciertas demandas y formas de lucha por no ser "realmente mapuche", como cuando en 2009 el delegado presidencial para asuntos indígenas, José Antonio Viera Gallo llamaba "a no confundir la noble causa mapuche con grupos anarquistas, que aparentemente estarían operando en la zona de Malleco". ${ }^{23} \mathrm{O}$ incluso en declaraciones tan cuestionables como las del historiador Sergio Villalobos al intentar deslegitimar la demanda mapuche aduciendo un fondo racial mestizo que en última instancia los volvería chilenos que simulan no serlo. ${ }^{24}$

23 Declaración a Radio Biobío del 9 de septiembre de 2009, http:// www.radiobiobio.cl/2009/09/09/proyecto-de-ley-que-permiteingreso-de-pueblos-originarios-al-congreso-estaria-listo-antes-delfin-del-gobierno-de-bachelet/. Accedido el 1 de diciembre de 2010.

24 Villalobos ha insistido con contumacia en este argumento de deslegitimación racial de una demanda mapuche. Cito aquí una de las más recientes. "Para empezar, hay que tener en cuenta que los araucanos, mal llamados 'mapuches', son mestizos con una fuerte carga blanca, igual que todos los chilenos de norte a sur. Somos descendientes de los conquistadores, los atacameños, los diaguitas, los picunches, los pehuenches, los huilliches y otras agrupaciones. Todos ellos han sido parte de una nación física y culturalmente unitaria, que ha construido una república exitosa" (Villalobos, Sergio 2017, "La Araucanía y sus falsedades", El Mercurio 15/01/2017.
Desde estas posiciones, cultura, espíritu o raza biológica fungen como las determinaciones en última instancia de unas demandas mapuche, una suerte de fondo prepolítico y prehistórico, al que la política mapuche (o sobre los mapuche) debe adecuarse como la copia respecto del original. El trabajo político supondría así un trabajo de traducción orientado por este fondo original y respecto del cual se podrán evaluar las diversas demandas en función de su mayor o menor fidelidad respecto del mismo, o dicho más platónicamente, mediante la discriminación entre las buenas copias y los malos simulacros. Es desde esta perspectiva que, como vimos, las comillas pueden significar esta desviación respecto de lo original perpetrada por la traducción, pero también vimos que las mismas comillas pueden indicar la potencia política del simulacro, extendiendo su capacidad de suspensión de un sentido original tanto antes como después de la traducción y de esta forma devolverle la dimensión histórica y contingente, es decir política, a ese fondo originario (racial, espiritual) supuestamente anterior a la política y a la historia.

Homi Bhabha trata este fenómeno, refiriéndose al deseo de integración o traducción colonial -que podríamos llamar villalobesca- del otro a sus propios códigos en los términos de un "mimetismo colonial", y al que entiende como "el deseo de un Otro reformado, reconocible, como sujeto de una diferencia que es casi lo mismo, pero no exactamente. Lo que equivale a decir que el discurso del mimetismo se construye alrededor de una ambivalencia; para ser eficaz, el mimetismo debe producir continuamente su deslizamiento, su exceso, su diferencia" (Bhabha 2002: 112). La noción de mimesis marcaría justamente el carácter ambiguo y contradictorio de este deseo colonial, 
o si se quiere el carácter de simulacro de esta traducción plena de la alteridad, en la medida en que no deja de afirmar la irreductibilidad política de su condición subalterna, condición que entiende como la producción del sujeto colonizado como un sujeto parcial por no acceder nunca a una identidad completa respecto del modelo colonizador (y que de esta forma nunca llegará a ser más que el simulacro de un "civilizado" puesto así entre comillas). Pero es en base a esta misma ambivalencia que el proceso mimético refluye y afecta los supuestos ontológicos que sostienen la mirada colonial: "la mirada de vigilancia retorna con la mirada desplazante del disciplinado, donde el observador se vuelve el observado y la representación 'parcial' rearticula toda la noción de identidad y la aliena de su esencia" (Bhabha 2002: 115). El mimetismo funcionaría entonces como interrupción de una noción colonial de la identidad, es decir, de aquella basada en la suposición de ese fondo prehistórico y prepolítico, y que, como escribe Bhabha, "no oculta ninguna presencia o identidad detrás de su máscara: no es lo que Césaire describe como 'colonización-cosificación' detrás de la cual está la esencia de la présence Africaine [o de una présence mapuche]. La menace [amenaza] del mimetismo es su doble visión que al revelar la ambivalencia del discurso colonial también perturba su autoridad" (Bhabha 2002: 114). Aplicado a un argumento como el de Villalobos, esta comprensión de la mimesis implicaría no la afirmación de un verdadero fondo racial, cultural o espiritual mapuche como alternativa ontológica y barrera a su propuesta de integración racial de su diferencia histórico-política, sino la develación del carácter igualmente simulado, es decir política y contingentemente construido por aparatos militares, administrativos, económicos e ideológicos, de algo como una chilenidad que además se supone anterior a las demandas que la cuestionan. $Y$ de hecho, la constitución de esos "archivos" mapuche, o el uso de esos uniformes que hacía de los longko decimonónicos unos "generales", pueden entenderse como la forma activa en que unos sujetos colonizados enfrentan miméticamente al orden colonial devolviéndole el poder desnaturalizante de sus comillas.

De esta forma podría decirse que en su uso actual, términos como werken o weichafe -o más recientemente el término machi también cargado de un potencial históricamente novedoso a la luz de la creciente visibilidad política que han adquirido en los últimos años ${ }^{25}$ no quedan más exentos de comillas que los términos "general" o "presidente" atribuidos a las autoridades mapuche de otras épocas. Recordemos que estos últimos señalan con sus comillas a la vez un gesto de traducción y su imposibilidad, es decir un simulacro de traducción no tanto por traicionar el sentido propio de un término supuestamente original, sino que por erosionar la supuesta propiedad del término que lo traduce (general o presidente). De la misma forma, y manteniéndose fieles a la potencia desnaturalizante, esto es politizante del simulacro entendido afirmativamente, podría decirse que los werken o weichafe contemporáneos también tienen la capacidad de poner entre comillas la originalidad ancestral de la que se supone están extrayendo su sentido.

\footnotetext{
Por nombrar sólo dos ejemplos particularmente visibles de esta emergencia de los y las machi como actores políticos relevantes, piénsese en el caso de la Machi Millaray Huichalaf condenada el año 2014 en el contexto de la lucha contra la instalación de una central hidroeléctrica en el río Pilmaiquén, o en el del machi Celestino Córdova condenado por el caso de la muerte del matrimonio Luchsinger Mackay y que el año 2017 entabló una huelga de hambre con el fin de acceder a su rewe para realizar la ceremonia de su renovación.
} 
De ahí que una noción tan recurrida actualmente como la del esencialismo estratégico quizás pueda entenderse como un "esencialismo" entre comillas, es decir un esencialismo mediante el cual se podría, eventualmente, erosionar el mandato multicultural que hace del intraducible indígena un fetiche de esas originalidades de lo humano desvirtuadas por los flujos homogeneizantes de la modernidad globalizada. $Y$ aquí es importante añadir que dicho mandato multicultural hace del intraducible un objeto de gestión capitalizable bajo la forma de ciertos montos de diversidad cultural, lo que de paso permite inmunizar los ordenamientos económicos trasnacionales como las estructuras soberanas nacionales contra las potencias políticas y desnaturalizantes del simulacro.

\section{Bibliografía}

Aburto Panguilef, M. 1928. "Reclamo no 355 de don celestino Quileñan y de su esposa doña Anjelina Meliñanco Reumai. sobre cuentos propios entre la raza araucana, o más bien dicho, hechicerías: temuco, octubre de 1928", vol. 7.321-1929, Santiago de Chile, Archivo Nacional de la Administración.

Alonqueo, M. 1979. Instituciones religiosas del pueblo mapuche. Santiago: Nueva Universidad.

1989. El habla de mi tierra. Temuco: Ediciones Kolping. sin fecha. Fonética. texto inédito, (5 pp), p. 1. Del archivo privado de la familia Alonqueo, Temuco.

Ancan, J. 2017. "A 25 años del Wenufoye. Una breve genealogía de la bandera nacional mapuche". Revsita Anales VII serie, 3: 283-305.

Benjamin, W. 2010. "La tarea del traductor". Obras IV. Madrid: Abada. 9-22.

Bhabha, H. K. 2002. El lugar de la cultura. Buenos Aires: Manantial.

Cassin, B. (directora) 2004. Vocabulaire Européen des philosophies. Dictionnaire des intraduicibles. París: Seuil/Le Robert.

Clavería, A. 2015. La estandarización escrita de lenguas indígenas en chile. Alfabetos e ideología, Tesis para optar al grado de Doctor en Antropología. San Pedro de Atacama: Universidad Católica del Norte.

Corte de Valdivia 1953, "Jurisprudencia seccion cuarta jurisdicción criminal. Corte de Valdivia, 7 de diciembre de 1953. Contra Juana Catrilaf". Revista de Derecho y Jurisprudencia, de Santiago de Chile, t. LII, julio y agosto de 1955, 5 y 6: 85-102.

El Diario Austral, 24 de septiembre de1931, Manuel Aburto Panguilef "Circular a todos los caciques".

El Diario Austral, 11 de septiembre de 1926, "el proyecto de división de tierras se considera salvador para la raza".

El Diario Austral 12 de diciembre de1953, "Desfile pintoresco. Con asistencia de millares de indígenas se efectuará hoy concentración nacional".

El Mercurio, 20 de enero de 1923, «Los fines que persigue la
Federación araucana de Loncoche (co- Ilimalliñ)».

Federación Araucana 1935, "Acuerdos del tercer congreso extraordinario de la Federación araucana: temuco, 31 de mayo de 1935", Loncoche: Archivo Museo Municipal de Loncoche.

Federación Araucana 1936, «Acuerdos de la sesión de 15 del presente mes, Temuco, 16 de marzo de 1936», Loncoche: Archivo Museo Municipal de Loncoche.

Foerster, R. Y M. Painemal. 1983. Martín Segundo Painemal. Vida de un dirigente mapuche. Santiago: GIA/Academia de Humanismo Cristiano.

Foerster R. y S. Montecino 1988, Líderes, contiendas y organizaciones mapuches. Santiago: CEDEM.

González Dinamarca, A. 2018. La invención de la cosmovisión mapuche y la antropología de María Ester Grebe. Tesis para optar al grado de Antropólogo social. Santiago: Universidad de Chile.

Grebe, M., S. Pacheco, S. y J. Segura, 1972, "Cosmovisión mapuche". Cuadernos de la Realidad Nacional, 14: 46-73.

La Época, 12 de julio de 1911, "Sociedad Caupolicán Defensora de la Araucanía."

La Nación 26 de diciembre de 1924, "Ayer se inauguró en la reducción de Huinquil, cerca de nueva imperial, el congreso araucano".

Lenz, R. 1910. "El arte de la traducción". Anales de la Universidad de Chile, vol. CXXVIII, CXXXI. Santiago de Chile.

Lévi-Strauss, C. 1952 (2002). Race et histoire. París: Gallimard.

Llaitul, H. Y J. Arrate. 2012. Weichan. Conversaciones con un weychafe en la prisión política. Santiago: Ceibo.

Manquilef, M. 1915. Las Tierra de Arauco. Temuco: Imprenta Modernista.

Menard, A. 2004, "La escritura y su resto (el suplemento mapuche)". Revista Historia Indígena 8: 57-88.

2006, "Emergencia de la tercera columna en el texto: 'La faz social' fragmento de los Comentarios del pueblo araucano de Manuel Manquilef. Presentación y comentario". Anales de desclasificación 2 (1): 927-937. 
2013, "Manuel Aburto y los archivos de la Federación Araucana", en Libro Diario del Presidente de la Federación Araucana, Manuel Aburto Panguilef (1940-1951). Menard, A. (Ed.). Santiago: CoLibris. xi-cxxix.

Menard, A. y J. Pavez. 2005. "El Congreso Araucano. Ley, raza y escritura en la política mapuche". Política 44: 211-232.

Radio Biobío, 9 de septiembre de 2009, http://www. radiobiobio.cl/2009/09/09/proyecto-de-ley- que-permite-ingresode-pueblos-originarios-al-congreso-estaria-listo-antes-del-findel-gobierno-de-bachelet/. (consultado en diciembre de 2010).

Schindler. H. 2006. Acerca de la espiritualidad mapuche. München: Martin Meidenbauer.

Villalobos, S. 2017. "La Araucanía y sus falsedades". E Mercurio 15/01/2017. 